\title{
False reports of an accomplice in a crime scene: conformity effects on memory confidence and accuracy
}

\author{
Rodrigo Fancz Pereira e Silva \\ Antonio Jaeger ${ }^{2}$ \\ ${ }^{1}$ Universidade Federal de Minas Gerais, Belo Horizonte, Minas Gerais, Brasil \\ ${ }^{2}$ FAE Centro Universitário, Curitiba, Paraná, Brasil
}

\begin{abstract}
The memory reports of a given individual may be altered by preceding memory reports of another individual, a phenomenon termed memory conformity. To investigate this phenomenon, 58 undergraduate students were separated in two groups which watched one of two slightly different movies of a crime scene (one included an accomplice). Subsequently, pairs containing one participant from each group discussed the movie, and then participants responded individually whether there was an accomplice in the scene. The frequency of false reports and their confidence for the presence/absence of the accomplice were analyzed. Only false reports of seeing an accomplice were produced (by $31 \%$ of those who saw no accomplice), and confidence were as high for these responses as for correct "no-accomplice" responses. The data is consistent with prior findings, and show that confidence on false reports can be high when involving "insertion" of elements to witnessed events.

Key words: Memory; Memory-conformity; Confidence.
\end{abstract}

Relatos falsos sobre um cúmplice na cena do crime: efeitos da conformidade na confiança e na acurácia da memória

\begin{abstract}
Resumo elementos em um evento testemunhado.

Palavras-chave: memória, conformidade de memória, confiança

Informes falsos de un cómplice en la escena del crimen: efectos de conformidad en la confianza y precisión de la memoria
\end{abstract}

O relato sobre fatos vivenciados por um indivíduo pode ser alterado por relatos anteriores apresentados por outro indivíduo, fenômeno denominado conformidade de memória. Para investigar esse fenômeno, 58 estudantes de graduação foram separados em dois grupos, os quais assistiram cada um a um vídeo ligeiramente diferente de um mesmo crime (em um havia um cúmplice). Posteriormente, foram formados pares de discussão contendo participantes que assistiram às diferentes versões do vídeo, para, em seguida, responderem individualmente sobre se havia um cúmplice na cena testemunhada. A frequência de relatos incorretos e a confiança na presença/ausência do cúmplice foi analisada. Somente relatos falsos da presença do cúmplice foram verificados (por 31\% daqueles que não viram o cúmplice no vídeo), e a confiança foi tão alta quanto as respostas corretas. Os resultados confirmam experimentos anteriores e mostram que a confiança em relatos falsos pode ser alta quando se trata de "inserção" de

\section{Resumen}

El informe de memoria sobre hechos vividos por un determinado individuo pueden ser modificados por informes de memoria de otro individuo, este fenómeno es denominado conformidad de memoria. Para investigar este fenómeno, 58 estudiantes universitarios fueron divididos en dos grupos, cada uno vio una película de una misma escena del crimen con sutiles diferencias (una de las versiones incluía un cómplice). Posteriormente, se conformaron parejas de discusión con un participante de cada grupo, y luego, de forma individual, cada persona contestó sí hubo un cómplice en la escena presenciada. Fue analizado la frecuencia de los informes falsos y su confianza en la presencia / ausencia del cómplice. Solo fueron analizados los informes falsos de la existencia del cómplice (por el 31\% de los que no vieron el cómplice en el video), y la confianza fue tan alta para estas respuestas, como para las respuestas correctas de "no cómplices". Los resultados confirman los experimentos anteriores y muestran que la confianza en los informes falsos puede ser alta cuando se trata de "insertar" elementos en los eventos atestiguados.

Palabras clave: Memoria; Conformidad de la memoria; Confianza.

Eyewitness testimonies are exposed to innumerable influences during and after witnessing the delict. Such exposition can lead to severe errors in the memory reports of the facts of a crime, and to the consequent contamination of the criminal proceedings. At the outset, the information provided by witnesses influences the line of investigation initiated by the investigators, who accordingly prepare photographs for recognition, search for the named suspects, take testimony from further witnesses, and formalize the requests for arrests in 
court, among other measures (Shaw, Garven, \& Wood, 1997). Thus, any errors or flaws in the memory reports can have serious consequences on the demarcation of the cause of the crime.

Several studies that investigated errors in memory reports have shown that when two individuals recall together an event they both witnessed, their reports are mutually influenced, even when significantly different aspects of the events are remembered by each individual (see Silva \& Jaeger, 2019, for a review). This phenomenon is known as memory conformity, whereby a person's account for an event is affected by another person's account for that same event (Jaeger, Lauris, Selmeczy \& Dobbins, 2012; Wright \& Villalba, 2012). In eyewitness testimony contexts, this phenomenon may be extremely harmful, since it may lead to inaccurate reports about criminal events (Wright, Self, \& Justice, 2000).

Research focusing on memory conformity has been reported for about two decades now, and has used different types of materials, such as pictorial (Wright et al., 2000; Goodwin, Kukucka, \& Hawks, 2013; Meade \& Roediger, 2002), and auditory stimuli (Mori \& Kishikawa, 2014; Oeberst \& Siedemann, 2014). Several memory conformity studies involved the presentation of short movies, and the interaction of a naïve participant with a confederate (i.e., typically an actress or actor). Specifically, the naïve participant and the confederate recall together information about the movie. In these studies, memory conformity is typically indexed by the influence of incorrect responses purposely given by the confederates on the responses given by the naïve participants (Saraiva et al., 2015; Shaw et al., 1997; Williamson, Weber, \& Robertson, 2013; Doughty, Paterson, MacCann, \& Monds, 2017; Daneman, Thannikkotu, \& Chen, 2013; Goodwin et al. 2013; Eisen, Gabbert, Ying, \& Williams, 2017; Gabbert, Memon, Allan, \& Wright, 2004; Blank et al., 2013; Zajac, Dickson, Munn, \& O’Neill, 2016; Meade \& Roediger, 2002).

Alternatively, numerous studies involved only naïve participants (i.e., they did not include confederates). Typically, in these studies, naïve participants are grouped in pairs wherein each participant is presented to a slightly different set of stimuli relative to the other (a slightly different movie, for example). The participants are unaware of such differences and are instructed to discuss the stimuli with their pairs, and later to respond to memory questionnaires or tests about those stimuli. Such manipulation consistently promotes memory conformity, which is indexed by participants reporting seeing items that were present only for the other participant form their pairs. Importantly, these manipulations have the advantage of being highly realistic, since no confederates are involved in the experiment (see Silva \& Jaeger, 2019, for a review).

A considerable part of these "naïve participants only" studies presented short movies as stimuli, but such movies were frequently silent (Gabbert, Memon, \& Allan, 2003; Valentine \& Maras, 2011; Bang, 2017; Bodner, Musch, \& Azad, 2009; Zajac et al., 2016; Hope, Ost, Gabbert, Healey, \& Lenton, 2007; French, Garry, \& Mori, 2008; Saraiva et al., 2015), an aspect that might not be ideal to engage participants in an immersive experience. In another set of studies engaging only naive participants, the researchers provided questionnaires to support and guide the participants' paired conversation about the witnessed event (Gabbert et al., 2003; Hope et al., 2007; Saraiva et al., 2015; Blank et al., 2013; French et al., 2008; Paterson, Kemp, $\& \mathrm{Ng} ; 2011)$, or informed the participants that they might receive false or inconsistent information about the event (Paterson, Kemp, \& McIntyre, 2012; Paterson et al., 2011). Finally, in further studies, researchers asked participants to recall information that were not evident in the stimulus event (French et al., 2008; Gabbert et al., 2004; Paterson et al., 2012; Paterson et al., 2011), or placed participants in a third person position, that is, participants watched a video similar to a security camera footage (i.e., the camera was static; Shaw et al., 1997; Williamson et al., 2013; Dalton \& Daneman, 2006; Blank et al., 2013; Daneman et al., 2013; French et al., 2008). Even though all these manipulations are informative, and produce typical memory conformity effects, they still may leave the participant somewhat disengaged from the criminal event. An alternative approach is to promote a more immersive experience for the participants, which is the experience we attempt to promote in the current study (see below).

Importantly, a current discussion in the memory research literature, which is particularly important for memory conformity, is the interaction between accuracy and confidence (Roediger, Wixted, \& DeSoto, 2013). The broader question here is whether confidence on memory reports is a reliable index of memory accuracy (Roediger \& DeSoto, 2015). In other words, when individuals are highly confident about remembering specific information about a given event, are such memories likely to be accurate? This question has been experimentally studied in the last few years (for a review, see Wixted \& Wells, 2017), and the general outcome of 
such research is that there is a strong positive correlation between confidence and accuracy. Importantly, however, recent research shows that such association may fail when witnesses are exposed to misinformation before providing their testimony accounts (i.e., in memory conformity contexts; Jaeger, Queiroz, Selmeczy, \& Dobbins, 2020; Souza \& Jaeger, 2019). That is, the typical positive correlation between accuracy and confidence for memory reports (Dunlosky \& Metcalfe, 2009) is not held in memory conformity experiments, with confidence for correct "old" responses being unaffected and confidence for "new" responses being affected by misinformation presented at the time of memory judgments (e.g., Jaeger \& Xavier, 2016).

Because in real testimony contexts eyewitnesses are exposed to a myriad of information, and often incorrect information given by other eyewitnesses, or even by their interviewers, the effects of memory conformity on memory accuracy and memory confidence emerges as a particularly important topic for research. Therefore, in the current study we focused on assessing the confidence on false memory reports produced after the interaction between the "eyewitness" and other testimonies (both naïve participants), an issue that has yet to be approached in a more realistic manner relative to prior research (e.g., Jaeger, Queiroz, Selmeczy, \& Dobbins, 2020).

In sum, the present experiment proposes an approach wherein (a) participants are exposed to an immersive experience, with audio and high definition video; (b) a face-to-face eyewitness discussion is witnessed in the first person, that is, the movies were filmed from a moving camera which followed the interaction of the actors in the crime scene, with the goal of creating the sensation that the viewer is walking around the crime scene; (c) confederates or researchers are not involved in the paired discussions, ensuring a more legitimate social interaction; (d) the stimuli are well-defined and presented centrally to the visual field of the participants. Thus, we expected to replicate the memory conformity effect in this context and focused specifically in the memory of participants about the presence or absence of an accomplice to the aggressor, and their confidence on their potential "incorrect" reports.

\section{Method}

\section{Participants}

Eighty-five undergraduate students from business, accounting, and law courses were invited to participate.
The experiment was conducted at a private university, in southern Brazil, and lasted approximately $50 \mathrm{~min}$ utes. The project was referred to the university's Ethics Committee for Research with Human Beings, where the necessary authorizations for execution were obtained. With respect to ensuring individual autonomy, a consent form was read, explained, and distributed to all participants. After clarifications, 61 students agreed to participate in the experiment, signed the consent forms, and were send to two different rooms. In order to establish the pairs of participants for the second part of the experiment, 1 participant was eliminated randomly from the study, leaving a total of 60 participants for the experimental manipulation. From the 60 consent forms answered after the video, 2 of them were printed incomplete and did not contain a front and back, one from Group A and the other from Group B, and both were discarded. Thus, the results are relative to 29 participants from each group $(n=29$ for each group, $n=$ 58 in total).

\section{Materials}

Stimulus: Movie 1. Movie 1 begins with the camera walking towards three people (one man and two women) sitting around a wooden table, apparently studying. About six meters away from this table (farther away than the camera), there is a man sitting on a ladder checking his cell phone, as well as another man on foot, also checking his cell phone. The man sitting on the stairs wore jeans and had a beard and hair bun, while the one standing was dressed in a black T-shirt, dark jeans, and sunglasses.

The film is in the first person perspective, and proceeds for about twenty seconds as if the witness were walking. An offensive shout aimed at the standing man is heard, whereupon the footage is redirected to show another man with short hair, blue jeans, and a striped gray shirt entering the scene. This man walks toward the standing man and starts a discussion in which the argument is related to a car crash.

At this moment, the man sitting on the stairs stands up and comes toward the two men for an instant, as if to intervene, but then leaves the scene. The discussion, from the moment of the initial shout to the end (when the aggressor apparently pushes an object into the victim) lasts about twenty seconds. Upon receiving the blow, the victim falls, and the attacker throws the object used in the attack on the ground and runs off, gets into a vehicle, and drives off. The three people who were 
sitting studying at the table also leave after witnessing the occurrence. The total video time is 57 seconds.

Stimulus: Movie 2. In Movie 2, the footage is very similar to Movie 1, especially its beginning. In this scene, the camera walks in the direction of three people (one man and two women) who are sitting around a wooden table, apparently studying. About six feet away from the group (farther away than the camera), there is a man standing, dressed in a black T-shirt, dark jeans, and dark glasses, tinkering with his cell phone. Thus, the first difference between the two videos is that in Movie 2, there is no one sitting on the stairs.

The image continues for about nineteen seconds, as if the witness were walking. An offensive shout directed at the standing man is heard, and following the sound, the footage is redirected to show two men entering the scene. One of the men has short hair, blue jeans, and a striped gray shirt, the other wearing a pair of jeans, with a beard and a bun in his hair. Both go toward the man who was standing and an argument begins, in which the screams are related to a car crash.

The central difference between the movies is explicit at this point because the main aggressor appears with an accomplice, whereas in Movie 1 he was the man sitting on the stairs. That is, in this second video, the man dressed in jeans with a bun in his hair is no longer a mere spectator but rather pushes the victim, thus assuming from the beginning the position of the accomplice of the aggressor.

In the rest of the scene, the man in the gray striped shirt pushes an object into the victim, who falls to the ground, while the attacker discards the object used in the attack and runs off with his accomplice, entering a vehicle. The discussion, from the moment of the initial shout to the end (when the subject apparently pushed an object into the victim) lasts about 24 seconds. The three people who were sitting studying at the table also leave after witnessing the event. The total video time is 58 seconds.

Questionnaire. After watching the movie and discussing it with a partner, participants filled in a form, named the Interview Form (see appendix), which asked for the following details about the movie, (1) in what time of day it occurred, (2) what the weather was like, (3) whether there was an argument, (4) in the case there was an argument, what was the reason for the argument, (5) whether the attacker had an accomplice (6) how many people witnessed the argument or aggression, (7) how long the argument lasted, and, finally, (8) an openended question to describe the parties involved in the crime. Participants also had to indicate their confidence in each response on a 5 -point Likert scale: $1=$ "very low confidence in your response," 2 = "low confidence in your response," 3 = "medium confidence in your response," 4 = "high confidence in your response," and $5=$ "very high confidence in your response."

\section{Procedures}

The 60 students were separated into two rooms, with 30 participants in each, which were named Group A and Group B. Participants were told that separation in two different rooms was necessary for reasons of space, since the 60 participants would not fit comfortably in the same room. The two rooms used were equipped with a video projector, audio device, and seating arrangement for each participant. To ensure that the instructions of the experiment were followed correctly and to prevent undue conversation in the course of the experiment, there was an assistant in each room in addition to the responsible researcher. After being separated into the two groups, participants were asked not to communicate in any way during or after the short movie.

Unaware that the videos were distinct, the 30 participants of Group A attended to Movie 1, while the 30 participants of Group B attended to Movie 2.

After the videos were shown, pairs were formed between participants from each of Groups A and B. The pairs were formed with people who did not know each other and who were instructed to talk exclusively about the scene they had viewed for six minutes in the following terms: "Now you will talk to each other about the crime you have just witnessed, and after the discussion, for which you will be given six minutes, you will be asked questions about the scene."

It was decided not to apply an initial form before the discussion for three reasons: (1) responding to a questionnaire shortly after watching the video would not reflect authentic social interactions (the goal of this research) because normally when a crime is witnessed, witnesses begin talking about it immediately, and only later they report what they saw to the police authorities; (2) responding to a questionnaire immediately after the fact can lead the participants to consolidate their experiences and avoid changing their responses as they remember what they have answered; and (3) for the purposes of comparing the answers (right or wrong), the participants had already been qualified, that is, it was known which video each participant watched. 
There was no intercurrence during the discussion, and all the pairs effectively discussed the scene during the time provided. After the discussion in pairs, the participants were informed that they could no longer talk to each other. Then, the participants received the Interview Form, which was to be filled individually and based exclusively on their own perceptions, as if they were providing a deposition to a police authority. Such an instruction was intended to eliminate the effect of normative influences so that the answers could more accurately elicit the participant's own memory.

\section{Data Analysis}

The data analysis focused on the accuracy with which participants remembered whether there was an accomplice in the movie they watched, and on the confidence participants had about the presence or absence of the accomplice in those movies. Thus, specifically to analyze accuracy, the frequency with which groups A and $\mathrm{B}$ responded positively for item 5 of the interview form (i.e., did the aggressor have an accomplice?) was recorded, and then converted to percentages. To analyze confidence, we estimated the overall mean confidence based on the confidence reported by each participant on item 5 of the interview form. Note that the confidence responses were given in a 1 to 5 scale, thus the ratings from all participants of each group were averaged, resulting in a mean confidence for each group.

\section{Results}

The results show that in the current paradigm a strong memory conformity effect emerged. Specifically, $31 \%$ of the participants who watched the "no-accomplice" movie (Group A), stated in the questionnaire having seeing an accomplice with the aggressor at the time of the aggression. That is, 9 out of 29 subjects of Group A stated that the aggressor acted with an accomplice. Interestingly, however, none of the participants who watched the movie in which the aggressor is actually accompanied by an accomplice (Group B) stated not seeing the accomplice at the aggression scene. The memory conformity found here, therefore, consisted only in adding a person to the witnessed event, and not to "forgetting" seeing a person in that event.

Furthermore, considering the responses to the critical question given by the participants of Group A (i.e., without accomplice), the average confidence of the nine participants who incorrectly conformed their answers was $4.11(S D=1.05)$, while the average confidence of the participants who did not conform their answers was $4.31(S D=0.88)$. The difference between these two means is not significant, $t(26)=0.54, p=0.576$. Interestingly, the mean confidence on the responses to the critical question reported by the participants who correctly claimed seeing an accomplice in the scene was of $4.76(S D=0.69)$, which was statistically higher than the mean confidence on the incorrect responses about the presence of an accomplice (i.e., false claims that there was an accomplice) reported by the group who had not seen the accomplice, $t(35)=2.16, p=0.037$, but only marginally different from the mean confidence on correct "no accomplice" responses reported by the group who had not seen the accomplice, $t(45)=1.94$, $\mathrm{p}=0.058$.

In sum, beyond showing that the typical memory conformity effect is replicated here, we show that confidence for false reports of an accomplice was indistinguishable from confidence for correct reports of the absence of an accomplice. In contrast, confidence for false reports of an accomplice was significantly lower than confidence for correct reports of an accomplice. Below we discuss these findings in light of the memory conformity literature.

\section{Discussion}

In the current study, we investigated whether information shared by two witnesses who watched different scenes can cause the witnesses to influence each other's memory and confidence on their memory reports. Using a task that promoted an immersive experience of witnessing a crime, we found that about one third of the participants who saw the scene with a single perpetrator, claimed that the perpetrator acted with an accomplice after discussing the scene with a person who had actually seen an accomplice. Importantly, we found that those participants were as confident about the presence of an accomplice as the participants who have correctly responded that there was no accomplice in the scene, although significantly less confident than the participants who saw the accomplice and correctly reported that there was an accomplice in the scene.

The findings regarding the false reports of an accomplice in the scene corroborate prior memory conformity studies that used different albeit similar experimental manipulations (e.g., Saraiva et al., 2015; Gabbert et al., 2003; Paterson et al., 2011; Zajac et al., 2016; French et al., 2008; Wright et al., 2000; see Silva $\&$ Jaeger, 2019). Thus, the current replication of the 
typical memory conformity effect is important to attest the generalizability of this phenomenon (Yarkoni, 2019), and to demonstrate that it can be produced in a variety of cultural contexts (Bang et al., 2017).

Interestingly, memory conformity was only evident for individuals who had not seen the accomplice. That is, none of those who watched the movie in which there was an accomplice were persuaded by their pairs to report that there was no accomplice in the scene. This finding reproduces an intriguing effect previously reported in the memory conformity literature, which consists in an asymmetry in the magnitude of memory conformity according to whether memoranda is "old" or "new" (Wright et al. 2000). In other words, individuals are more likely to conform by incorporating false information to their memory reports, than by failing to report something that was actually seen (Wright et al., 2005).

The current confidence data is consistent with these asymmetrical "old/new" effects. That is, mean confidence on false reports claiming the presence of an accomplice in the scene was statistically indistinguishable from mean confidence on accurate reports asserting the absence of an accomplice in the scene. Furthermore, these findings reflect prior research showing that confidence on "new" (or "absent") responses are in general lower than confidence on "old" (or "present") responses (Wright et al., 2005). This pattern has been replicated with different experimental tasks in different cultural contexts and populations (Rodrigues \& Jaeger, 2018; Zawadzka, Krogulska, Button, Higham, \& Hanczakowski, 2016; Jaeger \& Xavier, 2016; Jaeger, Selmeczy, O'Connor, Diaz, \& Dobbins, 2012).

Similarly, in a recent report, Jaeger, Queiroz, Selmeczy, and Dobbins (2020) showed that while confidence ratings for "new" responses are relatively low and modulated by external cues (cues that are analogous to responses provided by another person), confidence ratings for "old" responses are relatively high and unaffected by external cues. More importantly on their findings, and relevant for the current discussion, is the fact that such asymmetrical effect of memory conformity for "old" versus "new" information was independent of whether responses were correct or incorrect. That is, confidence on both accurate and inaccurate "old" responses were unaffected by external information (i.e., irresponsive to conformity), whereas confidence on both accurate and inaccurate "new" responses were similarly affected by external information (i.e., responsive to memory conformity). Thus, the data reported by those authors are consistent with the current findings in the sense that when an individual have the experience of retrieving a previously encountered information, it does not matter whether that information is correct or incorrect, their confidence on that report is going to be relatively high.

Here, however, even though the confidence reports for the false claims about the presence of accomplice were generally high, it was not as high as the mean confidence on the correct reports asserting the presence of the accomplice. This suggests that although incorrect reports following memory conformity can be asserted with high confidence, correct reports of seeing the accomplice in the scene were asserted with even greater confidence. This is consistent with the memory literature showing that confidence and accuracy are positively correlated (e.g., Dunlosky \& Metcalfe, 2009; Wixted \& Wells, 2017). However, when the translation of these experimental findings to real testimony contexts are considered, such difference might become uninformative (Roediger, Wixted, \& DeSoto, 2013). From the point of view of the current findings, the reason for that is that the participants who made false reports, still showed an overall high confidence on their responses. Indeed, 4 out of the 9 participants that incorrectly reported the presence of an accomplice rated their responses with maximum confidence. In actual testimony contexts, investigators often must rely on the report of only one eyewitness for a given investigation, and considering the number of investigations requiring the testimony of eyewitnesses, the frequency of high confidence false reports in real testimony contexts should be considerably high. Thus, caution should be taken here when the differences between these means (i.e., 4.11 vs. 4.31 ) are translated to real testimony contexts.

In sum, we replicated here the typical memory conformity effect, although we showed that such effect emerged only in the form of an "insertion" of information that was not actually seen (i.e., claiming that there was an accomplice when there was not). The confidence analysis corroborated this finding and evinced that such "insertion" may be reported with as much confidence as "absent" accurate responses, although correct claims about the presence of the accomplice were reported with significantly higher confidence. These findings have serious implications for the eyewitness testimony literature, since it is well demonstrated that judges and jurors believe that the higher the confidence exposed by witnesses, the more accurate the testimony is (Lacy 
\& Stark, 2013; Wells, Lindsay, \& Ferguson, 1979; Roediger, Wixted, \& Desoto, 2013).

\section{Conclusion}

In the current study, about one third of the participants who had not seen an accomplice in the crime scene, incorrectly reported the presence of an accomplice after discussing the scene with a participant who actually saw an accomplice. We show here that the participants made such "insertion" confidently, a finding that supports the notion that when individuals report recalling a given information (instead of not recalling it), their confidence is high, despite whether such recall is false or not. This finding also raises serious doubts about the utility of confidence reports in real testimony contexts, where a high confidence false recall can have tragic consequences. A limitation of the current study is that we did not collect demographic information from the participants, such as age and sex, although all of them were undergraduate students. Recruiting different age and education groups would be of great importance to verify how generalizable are the current findings. Furthermore, since in real testimony contexts the interviews are conducted long after individuals witnessed criminal events, future research should verify whether the current effects hold (or perhaps become stronger) after longer delays between watching the video, discussing the video, and responding to the questionnaire.

\section{References}

Bang, S. I. (2017). A cross-cultural examination of the conformity effect when co-witnesses discuss a crime. CUNY Academic Works, 37.

Blank, H., Ost, J., Davies, J., Jones, G., Lambert, K., \& Salmon, K. (2013). Comparing the influence of directly vs. indirectly encountered post-event misinformation on eyewitness remembering. Acta Psychologica, 144, 635-641. DOI: 10.1016/j. actpsy.2013.10.006.

Bodner, G. E., Musch, E., \& Azad, T. (2009). Reevaluating the potency of the memory conformity effect. Memory \& Cognition, 37(8), 1069-1076. DOI: 10.3758/MC.37.8.1069.

Dalton, A. L., \& Daneman, M. (2006). Social suggestibility to central and peripheral misinformation. Memory, 14(4), 486-501. DOI: 10.1080/09658210500495073.
Daneman, M., Thannikkotu, C., \& Chen, Z. J. (2013). Are there age-related differences in social suggestibility to central and peripheral misinformation? Experimental Aging Research, 39, 342-369. DOI: 10.1080/0361073X.2013.779201.

Doughty, N., Paterson, H. M., MacCann, C., \& Monds, L. A. (2017). Personality and memory conformity. Journal of Individual Differences, 38(1), 12-20. DOI: 10.1027/1614-0001/a000217.

Dunlosky, J., \& Metcalfe, J. (2009). Metacognition. New York, NY: Sage Publications.

Eisen, M. L., Gabbert, F., Ying, R., \& Williams, J. (2017). "I think he had a tattoo on his neck": How co-witness discussions about a perpetrator's description can affect eyewitness identification decisions. Journal of Applied Research in Memory and Cognition, 6, 274-282. DOI: 10.1016/j.jarmac.2017.01.009.

French, L., Garry, M., \& Mori, K. (2008). You say tomato? Collaborative remembering leads to more false memories for intimate couples than for strangers. Memory, 16(3), 261-273. DOI: $10.1080 / 09658210701801491$.

Gabbert, F., Memon, A., Allan, K., \& Wright, D. B. (2004). Say it to my face: Examining the effects of socially encountered misinformation. Legal and Criminological Psychology, 9, 215-227. DOI: 10.1348/1355325041719428.

Gabbert, F., Memon, A., \& Allan, K. (2003). Memory conformity: Can eyewitnesses influence each other's memories for an event? Applied Cognitive Psychology, 17, 533-543. DOI: 10.1002/acp.885.

Goodwin, K. A., Kukucka, J. P., \& Hawks, I. M. (2013). Co-witness confidence, conformity, and eyewitness memory: An examination of normative and informational social influences. Applied Cognitive Psychology, 27, 91-100. DOI: 10.1002/acp.2877.

Hope, L., Ost, J., Gabbert, F., Healey, S., \& Lenton, E. (2008). "With a little help from my friend...": The role of co-witness relationship ins susceptibility to misinformation. Acta Psychologica, 127, 476-484. DOI: $10.1016 /$ j.actpsy.2007.08.010.

Jaeger, A., Lauris, P., Selmeczy, D., \& Dobbins, I. G. (2012). The costs and benefits of memory conformity. Memory \& cognition, 40, 101-112. DOI: 10.3758/s13421-011-0130-z. 
Jaeger, A., Queiroz, M. C., Selmeczy, D., \& Dobbins, I. G. (2020). Source retrieval under cueing: Dissociated effects on accuracy versus confidence. Journal of experimental psychology. Learning, memory, and Cognition. DOI: $10.1037 / \mathrm{xlm} 0000826$

Jaeger, A., Selmeczy, D., O’Connor, A. R., Diaz, M., \& Dobbins, I. G. (2012). Prefrontal cortex contributions to controlled memory judgment: fMRI evidence from adolescents and young adults. Neuropsychologia, 50, 3745-3756. DOI: 10.1016/j. neuropsychologia.2012.10.022

Jaeger, A., \& Xavier, G. F. (2016). Recognition judgments under risk: Low confidence when certainty is low. Learning and Motivation, 56, 65-72. DOI: 10.1016/j.lmot.2016.09.006

Lacy, J. W., \& Stark, C. E. L. (2013). The neuroscience of memory: Implications for the courtroom. Nature Reviews Neuroscience, 14, 649-658. DOI: 10.1038/ nrn3563.

Meade, M., \& Roediger, H. (2002). Exploration in the social contagion of memory. Memory \& Cognition, 30, 995-1009. DOI: 10.3758/BF03194318.

Mori, K., \& Kishikawa, T. (2014). Co-witness auditory memory conformity following discussion: A misinformation paradigm. Perceptual \& Motor Skills, 118(2), 533-547. DOI: 10.2466/24.22. PMS.118k22w4.

Oeberst, A., \& Seidemann, J. (2014). Will your words become mine? Underlying processes and cowitness intimacy in the memory conformity paradigm. Canadian Journal of Experimental Psychology, 68(2), 84-96. DOI: 10.1037/cep0000014.

Paterson, H. M., Kemp, R. I., \& Ng, J. R. (2011). Combating co-witness contamination: Attempting to decrease the negative effects of discussion on eyewitness memory. Applied Cognitive Psychology, 25, 43-52. DOI: 10.1002/acp.1640.

Paterson, H. M., Kemp, R., \& McIntyre, S. (2012). Can a witness report hearsay evidence unintentionally? The effects of discussion on eyewitness memory. Psychology, Crime \& Law, 18, 505-527. DOI: 10.1080/1068316X.2010.510117.

Rodrigues, G. S., \& Jaeger, A. (2018). Source Memory and Cognitive Control in Gurdjieff Meditators. Mindfulness, 9, 1736-1747. DOI: 10.1007/ s12671-018-0914-3
Roediger, H. L. III, \& DeSoto, K. A. (2015). Understanding the relation between confidence and accuracy in reports from memory. In: Remembering: Attributions, processes, and control in human memory: Essays in honor of Larry Jacoby, 347-367. Psychological Press: New York.

Roediger, H. L. III, Wixted, J. H., \& Desoto, K. A. (2013). The curious complexity between confidence and accuracy in reports from memory. Memory and Law, 84-118. DOI:10.1093/ acprof:oso/9780199920754.003.0004.

Saraiva, R. B., Iglesias, F., Micas, G. F., Araújo, C. P. N., Lima, C. C., \& Costa, M. V. (2015). Conformidade entre testemunhas oculares: efeitos de falsas informações nos relatos criminais. Psico-USF, 20, 87-96.

Shaw, J., Garven, S., \& Wood, J. (1997). Co-witness information can have immediate effects on eyewitness memory reports. Law and Human Behavior, 21, 503-523. DOI: 10.1023/a:1024875723399.

Silva, R. F. P., \& Jaeger, A. (2019). Memory conformity and eyewitness testimony: a review. Revista Brasileira de Ciências Criminais, 152, 8-26.

Sousa, W. S., \& Jaeger, A. (2019). Conformidade de memória: A influência de respostas externas no reconhecimento de faces humanas (Dissertação de Mestrado). Universidade Federal de Minas Gerais - UFMG, Belo Horizonte,

Valentine, T., \& Maras, K. (2011). The effect of crossexamination on the accuracy of adult eyewitness testimony. Applied Cognitive Psychology, 25, 554-561. DOI: $10.1002 /$ acp. 1768 .

Wells, G. L., Lindsay, R. C. L., \& Ferguson, T. J. (1979). Accuracy, confidence, and juror perceptions in eyewitness identification. Journal of Applied Psychology, 64(4), 440-448.

Williamson, P., Weber, N., \& Robertson, M.-T. (2013). The effect of expertise on memory conformity: A test of informational influence. Behavioral Sciences and the Law, 31, 607-623. DOI: 10.1002/bsl.2094.

Wixted, J. T., \& Wells, G. L. (2017). The Relationship Between Eyewitness Confidence and Identification Accuracy: A New Synthesis. Psychological Science in the Public Interest, 18, 10-65. doi:10.1177/1529100616686966

Wright, D., Self, G., \& Justice, C. (2000) Memory conformity: Exploring misinformation effects when 
presented by another person. British Journal of Psychology, 91,189-202. DOI: 10.1348/000712600161781.

Wright, D., \& Villalba, D. (2012). Memory conformity affects inaccurate memories more than accurate memories. Memory, 20, 254-65. DOI: 10.1080/09658211.2012.654798.

Yarkoni, T. (2019). The generalizability crisis. PsyArXiv, $1-26$.

Zajac, R., Dickson, J., Munn, R., \& O’Neill, S. (2016). Trussht me, I know what I sshaw: the acceptance of misinformation from an apparently unreliable co-witness. Legal and Criminological Psychology, 21, 127-140. DOI: $10.1111 /$ lcrp.12032.

Zawadzka, K., Krogulska, A., Button, R., Higham, P. A., \& Hanczakowski, M. (2016). Memory, metamemory, and social cues: Between conformity and resistance. Journal of Experimental Psychology: General, 145, 181-199. DOI: $10.1037 /$ xge0000118

Recebido em: 29/01/2019 Reformulado em: 10/04/2019 Aprovado em: 14/03/2020 


\section{Appendix 1}

INTERVIEW FORM (Check with an X how confident you are, or how sure you are, about your answers and descriptions).

The crime occurred during day time or night time?

$(1)=$ very low confidence in your response, $(2)=$ low confidence in your response, $(3)=$ medium confidence in your response, (4) = high confidence in your response, (5) = very high confidence in your response.

How was the weather like?

$(1)=$ very low confidence in your response, $(2)=$ low confidence in your response, $(3)=$ medium confidence in your response, (4) = high confidence in your response, (5) = very high confidence in your response.

Did an argument happen?

$(1)=$ very low confidence in your response, $(2)=$ low confidence in your response, $(3)=$ medium confidence in your response, (4) = high confidence in your response, (5) = very high confidence in your response.

What was the reason of the argument?

$(1)=$ very low confidence in your response, $(2)=$ low confidence in your response, $(3)=$ medium confidence in your response, (4) = high confidence in your response, (5) = very high confidence in your response.

Did the aggressor had an accomplice?

$(1)=$ very low confidence in your response, $(2)=$ low confidence in your response, $(3)=$ medium confidence in your response, (4) = high confidence in your response, (5) = very high confidence in your response.

How many people witnessed the argument?

(1) = very low confidence in your response, $(2)=$ low confidence in your response, $(3)=$ medium confidence in your response, (4) = high confidence in your response, (5) = very high confidence in your response.

How long it took since till the argument to the runaway in the end?

$(1)=$ very low confidence in your response, $(2)=$ low confidence in your response, $(3)=$ medium confidence in your response, (4) = high confidence in your response, (5) = very high confidence in your response.

Describe the parties involved in the crime.

(1) = very low confidence in your response, $(2)=$ low confidence in your response, $(3)=$ medium confidence in your response, (4) = high confidence in your response, (5) = very high confidence in your response. 
About the authors:

Antônio Jaeger is a Professor da Universidade Federal de Minas Gerais (UFMG), e coordenador do Grupo de Pesquisa em Memória e Cognição. Doutor em Psicologia pela UFRGS com período sanduíche na Universidade da California, Irvine (UCI). Possui pós-doutorado pela Washington University in St Louis (EUA), PUCRS e USP. Pesquisa processos básicos de memória e aprendizagem sob uma perspectiva da Psicologia Cognitiva e Neurociência Cognitiva. ORCID: https://orcid.org/0000-0001-5093-6198

E-mail: antonio.jaeger@gmail.com

Rodrigo Faucz Pereira e Silva is a Professor of the Master's Program in Forensic Psychology (UTP) and Criminal Procedure at FAE Centro Universitário. PhD in Neuroscience from the Federal University of Minas Gerais. Master in Fundamental Rights and Democracy. Researches the formation of the conviction of judges and basic memory processes from the Neurosciences. Lawyer.

ORCID: https://orcid.org/0000-0001-7940-9316

E-mail: rodrigo@faucz.com.br

Contact:

Antônio Jaeger

Department of Psychology, Federal University of Minas Gerais

Antonio Carlos Avenue, 6627

Belo Horizonte-MG, Brazil

CEP: 31270-901

Phone: (55 31) 99527-8515 